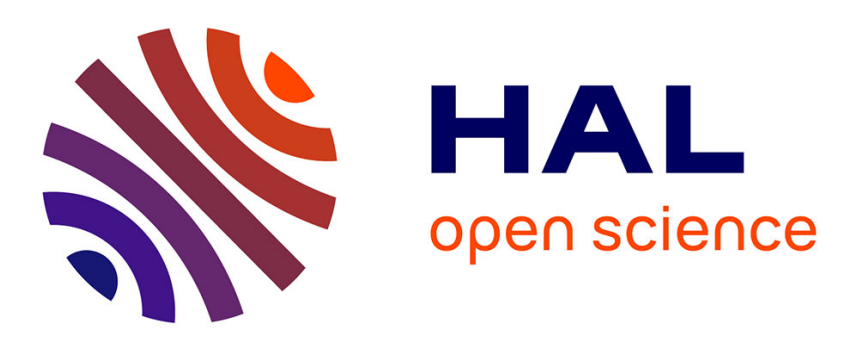

\title{
Private or Common Criteria in a Multi-criteria Group Decision Support System: An Experiment
}

\author{
Pascale Zaraté, Marc Kilgour, Keith Hippel
}

\section{To cite this version:}

Pascale Zaraté, Marc Kilgour, Keith Hippel. Private or Common Criteria in a Multi-criteria Group Decision Support System: An Experiment. International Conference on Collaboration Technologies (CRIWG 2016), Sep 2016, Kanazawa, Japan. pp. 1-12. hal-01475022

\section{HAL Id: hal-01475022 \\ https://hal.science/hal-01475022}

Submitted on 23 Feb 2017

HAL is a multi-disciplinary open access archive for the deposit and dissemination of scientific research documents, whether they are published or not. The documents may come from teaching and research institutions in France or abroad, or from public or private research centers.
L'archive ouverte pluridisciplinaire HAL, est destinée au dépôt et à la diffusion de documents scientifiques de niveau recherche, publiés ou non, émanant des établissements d'enseignement et de recherche français ou étrangers, des laboratoires publics ou privés. 


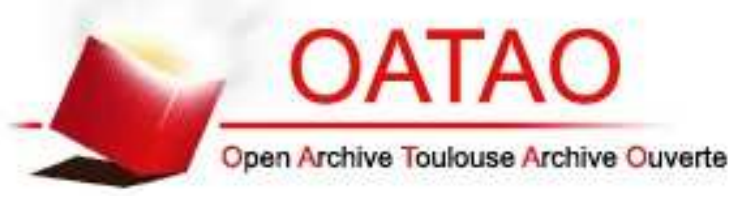

\section{Open Archive TOULOUSE Archive Ouverte (OATAO)}

OATAO is an open access repository that collects the work of Toulouse researchers and makes it freely available over the web where possible.

This is an author-deposited version published in : http://oatao.univ-toulouse.fr/ Eprints ID : 17175

The contribution was presented at CRIWG 2016 :

http://inolab.slis.tsukuba.ac.jp/global/criwg16/

To cite this version : Zaraté, Pascale and Kilgour, Marc and Hippel, Keith Private or Common Criteria in a Multi-criteria Group Decision Support System: An Experiment. (2016) In: International Conference on Collaboration Technologies (CRIWG 2016), 14 September 2016 - 16 September 2016 (Kanazawa, Japan).

Any correspondence concerning this service should be sent to the repository administrator: staff-oatao@listes-diff.inp-toulouse.fr 


\title{
Private or Common Criteria in a Multi-criteria Group Decision Support System: An Experiment
}

\author{
Pascale Zaraté $^{1(\sqrt{6})}$, D. Marc Kilgour ${ }^{2}$, and Keith Hipel $^{3}$ \\ ${ }^{1}$ IRIT, Toulouse University, Toulouse, France \\ pascale.zarate@irit.fr \\ 2 Wilfrid Laurier University, Waterloo, Canada \\ ${ }^{3}$ University of Waterloo, Waterloo, Canada
}

\begin{abstract}
Because collective decision processes are central to the management function of most organizations, it is important to understand them better and to improve them if possible. One common view of group decision processes is that they should offer participants the opportunity to confront and resolve the differences in their points of view. New cognitive and technical tools may help to facilitate the sharing of individuals' reasoning and preferences, but only if they do not require participants to reveal information that they wish to keep private, perhaps for strategic or personal reasons. The aim of this study is to test experimentally one such approach, contained in the Group Decision Support System, GRUS, which allows decision makers to use a multi-criteria approach to problem structuring that can involve both public (shared) and private criteria.
\end{abstract}

Keywords: GDSS - Multi-criteria group decision making · Private criteria · Public criteria

\section{Introduction}

In most organizations, important decisions are made after intensive consultations involving numerous decision makers, rather than by individuals acting on their own [1]. Smoliar and Sprague [2] discuss how interactions involving several actors are input into decision processes in organizations. This interaction, which includes but is not limited to the communication of information, is generally aimed at achieving a joint understanding among the decision makers.

Many authors have analyzed the process of group decision making from a range of perspectives. Zarate [3] demonstrated that the use of Information and Communication Technologies to support decisions within the increasing complexity of organizations implies a modification of decision processes, which become more complex and involve more actors. These modifications must be present both at the organizational level, with larger numbers of responsible actors, and at the individual level, as actors face the challenge of understanding and classifying information using new and more difficult cognitive processes. New kinds of decision processes, which could be called Collaborative Decision Making, are thus required. 
Simply put, within a collective framework decision makers may have difficulty balancing their own preferences with the development of common (group) preferences and a shared understanding. The purpose of this paper is to conduct an experiment to assess whether decision makers can feel comfortable with common preferences. This experiment is based on a multi-criteria approach using the Group Decision Support System GRoUp Support, or GRUS [4], and aims to assess the roles of private versus common (shared or collective) criteria. When do multi-criteria group decision processes work better? Under what circumstances are individuals more comfortable using private as opposed to common criteria and performance evaluations? Can we verify in practice that these advantages are significant and discover conditions that can strengthen them? More generally, we wish to observe how participants perceive the advantages of joint decision-making in a group multi-criteria approach.

This paper is structured as follows. In Sect. 2, the GRUS system is described. Then the experiment is set out, along with the hypotheses of our study, in Sect. 3. Next, in Sect. 4, the results of the experiment are analyzed, and then they are discussed in the Sect. 5, which compared our hypotheses to the experimental observations. Section 6 offers some concluding remarks and perspectives.

\section{Related Work}

Moulin [5] defined cooperative games as follows: "A cooperative game in society $N$ consists of a feasible utility set for the grand coalition $N$ as well as a utility set for each and every sub-coalition (non-empty subset) of $N$, including the coalitions containing one agent only." He then proposed a categorization of many Game Theory axioms. Inspired by his definitions, we define Collaborative Decision Processes as dynamic decision processes involving several actors, who may use Information and Communication Technologies, who interact not only by making moves but also by updating their information and beliefs as other participants move. For these Collaborative Decision Processes, the use of Group Decision Support Systems (GDSS) is called for, and the facilitation process takes a central place.

The facilitator role within group meetings has been studied for over 40 years. Facilitators contribute to the effectiveness of GDSS, making meetings more productive and efficient, by managing the content, the process, or the use of software, and sometimes all three. It is not surprising that facilitator know-how can made a great difference in the effectiveness of GDSS in practice. Bostrom et al. [6] try to answer to the question: "Is a facilitator necessary in GSS environments?" Even though researchers have promoted GSS as a substitute for a human facilitator, many answer "Yes" to the question; and Bostrom and co-authors conclude that a human facilitator is definitely required. They find that the important question is "How can different sources of facilitation (people, software) be combined to effectively design and support meetings?" Following this paradigm, Ackerman [7] proposed Strategic Options Development and Analysis (SODA) to group members (participants) who had used a GDSS for organizational decision making. SODA is indeed a methodology to guide participants during meetings. 
Even though the facilitation process has been well studied for several decades, several questions remain difficult to answer. What kinds of skills are necessary to facilitate Collaborative Decision Making? Can Collaborative Decision Processes be conducted with no human facilitation at all?

\section{The GRoUp Support System: GRUS}

GRUS is a free web platform, available at http://www.irit.fr/GRUS; it is protected by a login and a password available upon request from the authors. GRUS supports several kinds of meetings: synchronous or asynchronous, distributed or face-to-face. In case of a distributed asynchronous meeting, the decision making process must be managed by a facilitator as if it were a classical project by imposing an agenda.

GRUS is designed as a toolbox and is implemented in the framework Grails, which is based on the programming language Groovy, a very high level language like Python or Ruby. Groovy can be compiled to Java Virtual Machine bytecode and can interoperate with other java codes or libraries (for more details about these tools, see [4]). GRUS can be used by different users, including designers of collaborative tools (application developers), designers of a collaborative process (collaboration engineers), session facilitators (users of GRUS), and decision makers (users of GRUS).

GRUS offers the basic services commonly available in Group Decision Support System (GDSS) such as definition/design of a static or dynamic group decision process, management (add, modify, delete, etc.) of collaborative tools, and management of automatic reporting as PDF files.

GRUS is conceived as a toolbox including several collaborative tools supporting collaborative decision processes such as Brainstorming, Clustering, multicriteria Analysis, Voting, Consensus determination, and Reporting. Users of the multicriteria tools can define several criteria and several alternatives, and then give their assessment of each alternative on each criterion, thus creating what is called a preference matrix. Each preference is reported on a scale from 0 to 20 . The decision makers may also give their preferred weights for the criteria. To indicate these preferences, each decision maker must enter a suitability function, thereby defining his or her interpretation of each criterion. This is possible thanks to an indifference threshold. Finally, dependencies among criteria must also be taken into account. These dependencies are assessed by each decision maker on a scale from 0 to 20 for each pair of criteria.

Two aggregation techniques are implemented in the GRUS system. The first aggregation methodology is the weighted sum [8], under which dependencies among criteria are not taken into account. The second methodology is the Choquet Integral [9], which explicitly takes dependencies among criteria into account.

\section{Hypotheses of the Experiment}

One benefit of a group decision-making process is the sharing of information that supports the participants' preferences. If the participants announce their preferred alternative without providing arguments about why it is appropriate to the problem at hand, 
the process does not contribute to any deeper understanding of the problem, nor to better knowledge of the alternatives, nor the links between them. In other words, the decision does not benefit from being made by the group [10]. However, it may not be practicable for participants to share their reasoning, first because they may have personal information or considerations that they may not wish to divulge (due to strategic reasons or privacy concerns), and second because the reasons for their own preference may not be clear, even to themselves.

In the end, the result of a group decision-making process must be supported by a mix of objective and subjective reasons. To meet this requirement, Sibertin and Zaraté [11] proposed a methodology distinguishing collective criteria from individual criteria for the assessment of alternatives.

- According to Sibertin and Zaraté [11], a criterion is collective if the group participants agree on its relevance and on the score of each alternative on this criterion;

- A criterion is individual if it is considered relevant by one participant (or several, but not all), or if the participants do not agree on the scores of alternatives on this criterion.

Collective criteria contribute to the objective part of the group's assessment, while individual criteria contribute to its subjective part.

Hypothesis 1: In a collaborative decision making process, there are benefits from allowing participants to use private criteria as well as common criteria.

In order to achieve cohesion in the group and the consistency in the group decision, it is necessary to find a balance between the individual approach to the problem, i.e. the private criteria, and the collective approach, i.e. the common criteria.

Hypothesis 2: In a collaborative decision making process, the number of private criteria should at least equal the number of common criteria.

Collaborative decision making processes are generally supported by Group Decision Support Systems. The use of GDSS implies the need for group facilitation, defined as a process in which a person who is acceptable to all members of the group intervenes to help improve the way the group identifies and solves problems, and makes decisions [12]. Facilitation is a dynamic process that involves managing relationships between people, tasks, and technology, as well as structuring tasks and contributing to the effective accomplishment of the intended outcomes.

According to Ackermann and Eden [13], such facilitation helps groups to contribute freely to the discussion, to concentrate on the task, to sustain interest and motivation to solve the problem, to review progress and to address complicated issues rather than ignore them. A further task of facilitation is to engage the group in problem-formulation and creativity-enhancing techniques to bring structure to the issues they are facing [14]. Facilitators attend to the process of decision making, while the decision makers concentrate on the issues themselves.

Automated facilitation is the enrichment of a GDSS so as to guide decision makers toward successful structuring and execution of the decision-making process [15]. According to Nunamaker et al. [16], an electronic facilitator should execute four functions: (1) provide technical support by initiating and terminating specific software tools; 
(2) chair the meeting, maintaining and updating the agenda; (3) assist in agenda planning; and finally (4) provide organizational continuity, setting rules and maintaining an organizational repository.

Because many of these tasks seem difficult to automate, it would seem that it would be difficult for decision makers to use GDSS without a human facilitator.

\section{Hypothesis 3: GDSS use remains difficult without a human facilitator.}

A questionnaire was given to all participants. This questionnaire was composed of seven questions, five about the common/private criteria and two about the facilitation.

\section{The Experiment}

The experiment was conducted while the first author visited Wilfrid Laurier University and the University of Waterloo in Waterloo, Canada. A group of 15 persons, mostly $\mathrm{PhD}$ students and visiting researchers, was selected to participate in the experiment.

The experiment is described as follows:

A case-study decision problem was proposed, as described below.

"You are a member of the Administrative Committee of the Play-On-Line Company, which develops Software Games. Its primary staff includes 150 collaborators, as follows:

- $80 \%$ Computer Engineers

- $15 \%$ Marketing and Sales Staff

- $5 \%$ Administrative Staff.

During an earlier meeting, the Board decided to buy mobile phones for the entire staff (all the collaborators listed above) even though the usage of the phones will not be the same for the business staff, the engineers, and the administrative staff. The computer engineers need to test the software they develop on all kinds of operating systems, for example operating systems implemented on Androids or iPhones. The business staff will use their phones to demonstrate the software to potential clients (for example, they need large screens). Administrative needs are simpler, and include for example communication (email and text as well as phone calls).

The aim of the meeting today is to decide on the best solution for the Play-On-Line Company. The finances are strictly limited, so costs must be minimized. In order to satisfy the requirements of all stakeholders, your group must think up several solutions called scenarios. Nevertheless, the company's survival, from a financial point of view, is the highest priority. You can, for example, decide to buy the same smartphones for all users, or you could plan to buy different smartphones for different stakeholders, or use at least some smartphones exclusively for testing and assign others to the collaborators. The technical characteristics and prices of five preselected smartphones are given below.

First of all, you have to define the set of criteria (4 or 5) to solve this problem and several alternatives (4 or 5). One alternative is defined as a combination of several products, such as $80 \%$ of Smartphone A plus $20 \%$ of Smartphone B. You will be guided by 
the facilitator, and then you will enter in the GRUS system your own preferences that will be input to the group decision".

Using the GRUS system, the following process was applied:

- Brainstorming to generate criteria and alternatives (scenarios) electronically. Each decision maker's input is anonymous.

- Clustering to reduce the numbers of criteria and alternatives to 4 or 5 . This step is conducted by the facilitator orally. Each decision maker expresses their own views about the categorization of ideas. The facilitator then assigns each criterion to a category of criteria and each alternative to a category of alternatives.

- MultiCriteria Evaluation, in which each decision maker gives their own assessment, on a scale of 0 to 20, of the performance of each alternative on each criterion, the weight of each criterion, and a suitability function reflecting the interpretation of each criterion (i.e. an indifference threshold as well as the pair-by-pair dependencies among criteria).

- Direct Vote, in which all preferences given by all users are combined using two techniques, weighted sum and Choquet Integral. During this step, the facilitator shows the results of the Multi-Criteria Evaluation. All alternatives are then ranked according to the two techniques, producing two total orders. A discussion is then initiated by the facilitator in order to classify all alternatives into three categories: Saved, Possible, Removed.

- Conclusion in which the facilitator proposes a conclusion for the meeting - the set of saved alternatives. If the group must decide on one specific alternative, it is still possible to go back to the Multi-Criteria Evaluation step in order to refine the solution.

- Report. The facilitator generates a report of the meeting as a PDF file.

Finally, after this 1-h meeting, the participants were asked to fill out a questionnaire assessing these methods for identifying criteria and evaluating alternatives.

Three groups of five participants each were created. Each worked within a meeting session of $60 \mathrm{~min}$.

Figure 1 shows Experimental Group 2 carrying out the first step of the process, brainstorming on criteria and alternatives.

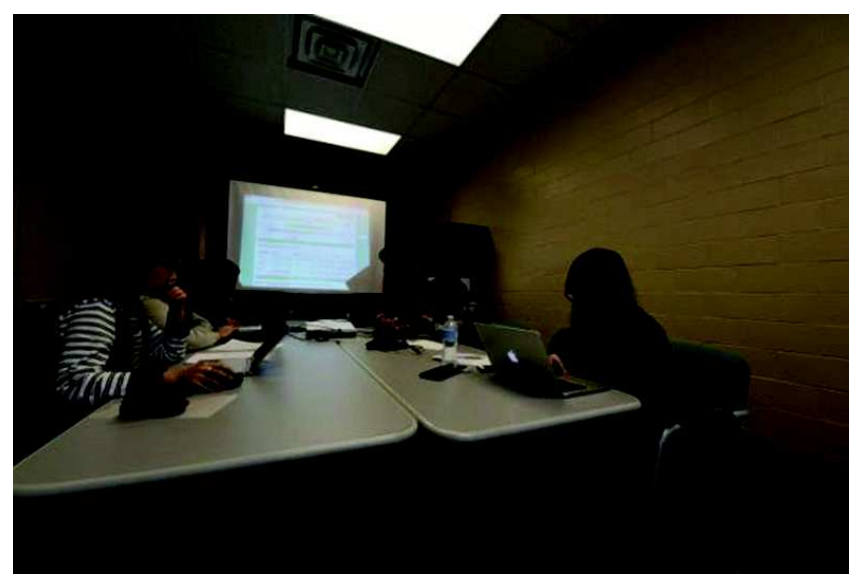

Fig. 1. Brainstorming step for Group 2 
Group 1 agreed on the following criteria: Price, Operating System, Communication Autonomy, Battery Capacity, and RAM; and generated 4 alternatives. Group 2's criteria were as follows: Price, Battery, Communication, and Operating System; and used 3 alternatives. Group 3 proposed as criteria: Price, Autonomy, RAM, and Handling; and defined 4 alternatives. All of this information is summarized in Table 1.

Table 1. Groups and Criteria

\begin{tabular}{l|l|l|l}
\hline Group number & Number of participants & Selected criteria & $\begin{array}{l}\text { Number of identified } \\
\text { alternatives }\end{array}$ \\
\hline 1 & 5 & $\begin{array}{l}\text { Price } \\
\text { Operating System } \\
\text { Communication } \\
\text { Autonomy } \\
\text { Battery Capacity } \\
\text { RAM }\end{array}$ & 4 \\
\hline 2 & 5 & $\begin{array}{l}\text { Price } \\
\text { Battery } \\
\text { Communication } \\
\text { Operating System }\end{array}$ & 3 \\
\hline 3 & & $\begin{array}{l}\text { Price } \\
\text { Autonomy } \\
\text { RAM } \\
\text { Handling }\end{array}$ & 4 \\
\hline & 5 & & \\
\hline
\end{tabular}

\section{Results}

The results for all groups are given in the following sections.

\subsection{Common/Private Criteria Results}

The questionnaire contained five questions about whether the decision makers felt comfortable using only common criteria. The participants answered on a 4-point scale, with one additional level for those who have no opinion: Completely agree, Rather agree, Rather disagree, Completely disagree, No opinion.

The first question was: Do you think it is difficult for the group to find a set of shared criteria? The results are shown in Fig. 2. No participant answered No opinion or Completely agree. A large majority ( $80 \%$, including those who chose Completely not agree or Rather not agree) thinks that it is not difficult to find shared criteria in a group.

The second question was: Do you think that group size makes it difficult for the group to find shared criteria? The results are shown in Fig. 3. No participant answered No opinion. A majority (60\%, including those who chose Completely agree or Rather agree) thought that the size of a group influences its ability to find shared criteria. 


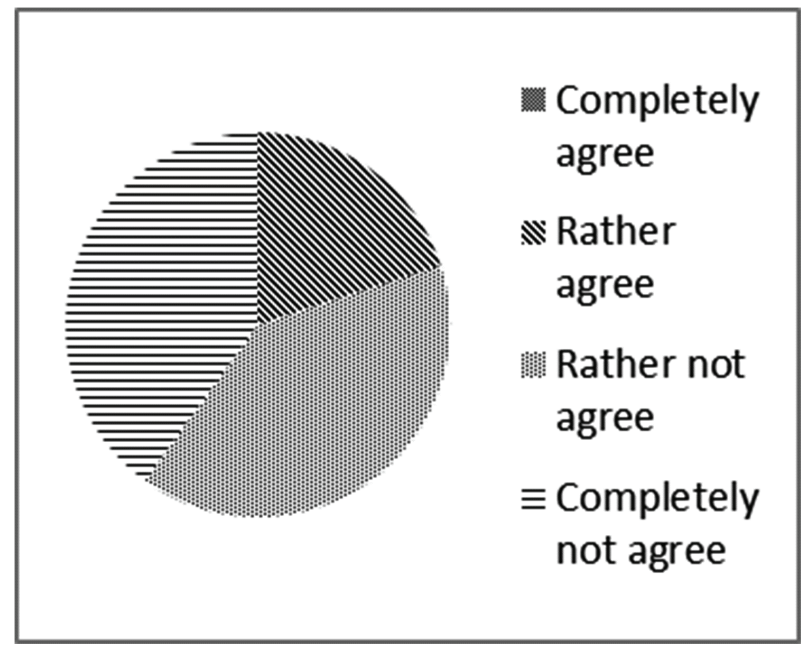

Fig. 2. Difficult to find shared criteria

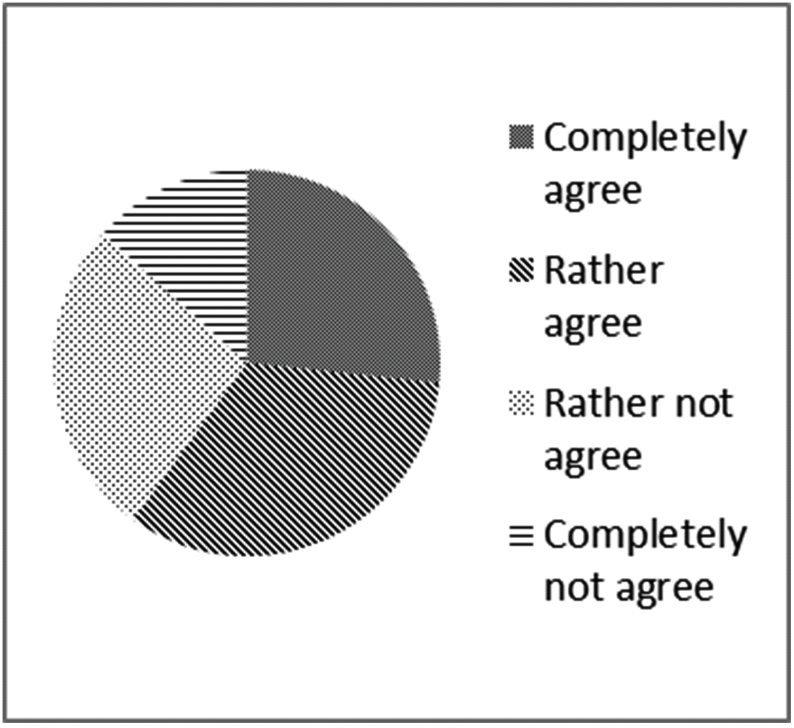

Fig. 3. Size of the group influences finding shared criteria

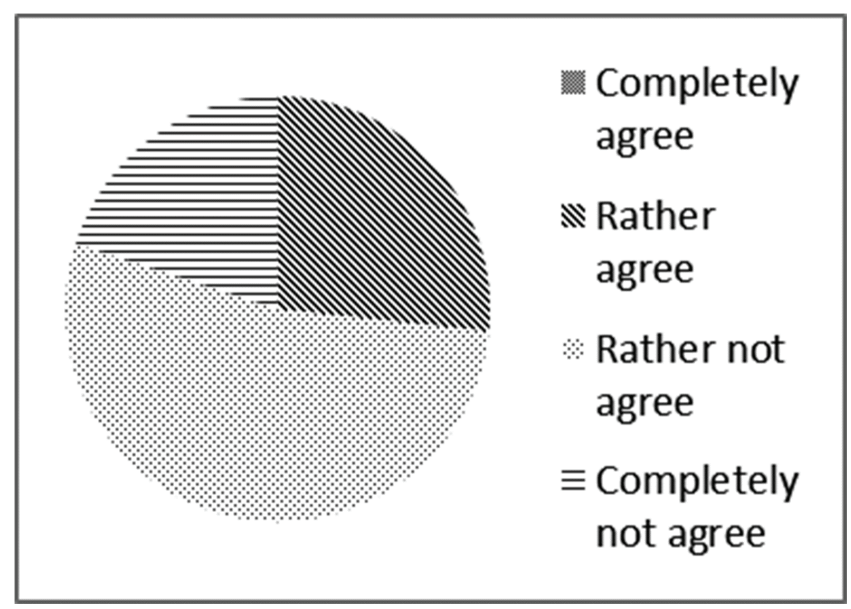

Fig. 4. Use private criteria 
The third question was: Do you think it should be mandatory for all group members to use the same criteria?

No participant answered No opinion or Completely agree. A majority (74 \%, including those who chose Rather not agree or Completely not agree) thought that it is not mandatory that the group work with the same criteria.

The fifth question was: Do you think that the number of private criteria for each decision maker should be at least as great as the number of shared criteria? The results are shown in Fig. 5.

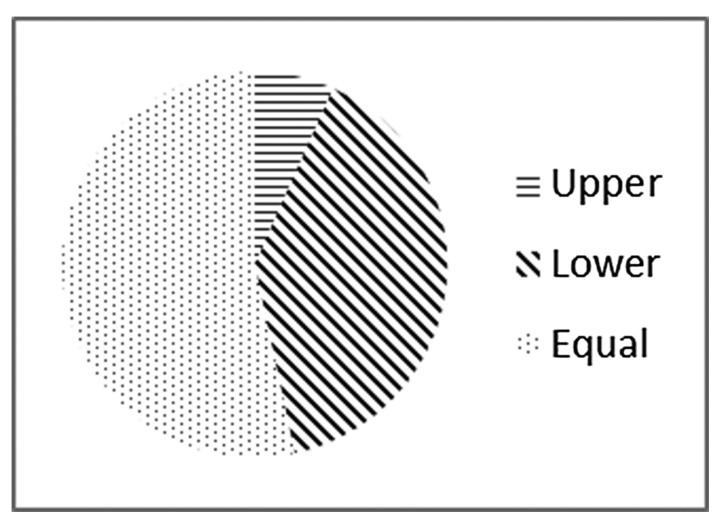

Fig. 5. Number of private criteria equal to number of shared criteria

No participant answered No opinion. A majority (53\%) thought that the number of private criteria should be the same as the number of shared criteria, but a large minority responded that the number of private criteria should be less than the number of public criteria $(40 \%)$.

\subsection{Facilitation Results}

Two questions about the facilitation process were asked to the stakeholders.

The participants answered on a 4-point scale, with one additional level for those who have no opinion: Completely agree, Rather agree, Rather disagree, Completely disagree, No opinion.

The first question was: Do you think that GRUS could be used without a facilitator? The results are shown in Fig. 6.

No participant answered No opinion. The result is balanced: $40 \%$ rather agree and $40 \%$ rather disagree with the idea that the system could be used without a human facilitator.

The second question was: Do you think that a decision process using the GRUS system is enough to support a group decision meeting? The results are shown in Fig. 7. 


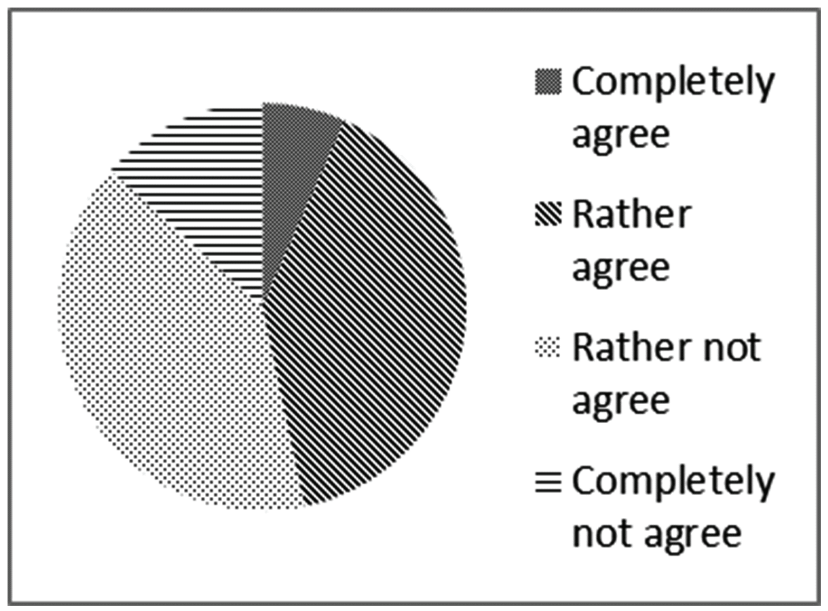

Fig. 6. Use of the system without a facilitator

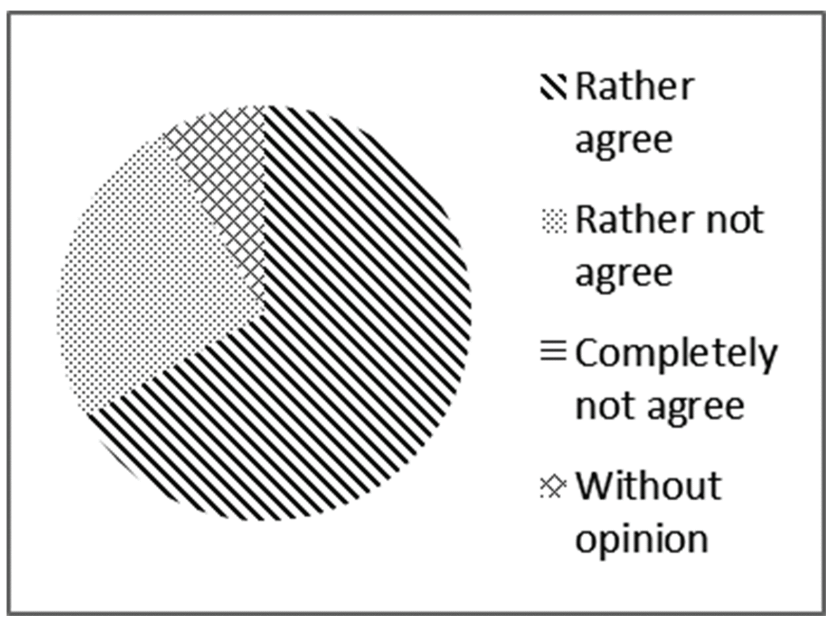

Fig. 7. Use of the system as a work process

One participant had no opinion. A large majority ( $74 \%$, including those who chose Completely agree or Rather agree) thought that the system could be used with a work process introduced in the GRUS system.

\section{Discussion}

The hypotheses were analyzed according to the results obtained in the experiment.

Hypothesis 1: In a collaborative decision making process, there are benefits from allowing participants to use private criteria as well as common criteria.

Most participants did not find it difficult to define shared criteria (see Fig. 1) and a small majority thought that the size of the group influences its ability to find common criteria (see Fig. 2). Referring to Fig. 3, a large majority believed that the group should not use only shared criteria and that the system worked better when participants could use private criteria. Based on these results, we conclude that Hypothesis 1 is confirmed. 
Next, the question is to determine the number of criteria to be used and the proportions of private and common criteria.

Hypothesis 2: In a collaborative decision making process, the number of private criteria should at least equal the number of common criteria.

The results given in Fig. 4 show that the majority thought that the number of private criteria should at least equal the number of common criteria. Forty percent of participants also indicated that the number of private criteria should be less than the number of common criteria. We conclude that Hypothesis 2 is partially confirmed, and recommend that the number of private criteria be equal to or less than the number of common criteria.

GDSS use is generally conducted by a facilitator who, it has been suggested, may be replaced by a computer system. The next hypothesis aims to assess the participants' reactions to GDSS with and without a human facilitator.

\section{Hypothesis 3: GDSS use remains difficult without a human facilitator.}

For Fig. 5, the results are balanced. Forty percent of the participants thought that a human facilitator would help, but forty percent felt that a human facilitator is not mandatory. Turning to Fig. 6, we can see that a large majority (74 \%) believed that an automated process implemented in the system could facilitate the decision making process. Therefore, we cannot interpret Hypothesis 3 as confirmed. We only can say that an automated process implemented to support the group could be helpful, but that a human facilitator may be at least equally effective.

\section{Concluding Remarks and Perspectives}

Group decisions can be complex and conflicting. Participants may feel dissatisfied and unmotivated, and they may not feel that their wishes and views have been properly considered. We have shown that using private and common criteria in Multi-Criteria Group Decision making can improve the participants' satisfaction with the process.

This study aimed to test the effects of using private and common criteria in group decisions. It addressed certain factors that should be considered carefully in designing a group decision process.

One such factor is the impact of the homogeneity of the group. Cohesive groups can agree more easily, especially if there are dominant leaders, and thereby limit creative solutions. Cultural effects could also have an influence on the results.

One limitation of this work is the low number of participants. In order to verify these first results, we will need to conduct more experiments.

Thus, our preliminary results should be checked using other experiments. We aim to conduct them in the near future, including in other countries. In addition to these new experiments, we plan to analyze all the experiments with respect to the demographic data of the participants (sex, age, occupation).

Another limitation of this first study is the analysis was conducted with students. These first results must therefore be verified with further experiments conducted in companies. 
Acknowledgement. The authors would like to thank the CIMI Excellence Laboratory, Toulouse, France, for funding the visit of Pascale Zaraté as Visiting Professor at Wilfrid Laurier University, Waterloo, Canada, during the period of December 2015 to February 2016.

\section{References}

1. Gorry, G., Morton, M.S.: A framework for management information systems. Sloan Manage. Rev. 13(1), 50-70 (1971)

2. Smoliar, S., Sprague, R.: Communication and understanding for decision support. In: Proceedings of the International Conference IFIP TC8/WG8.3, Cork, Ireland, pp. 107-119 (2002)

3. Zaraté, P.: Tools for Collaborative Decision-Making. John Wiley, Hoboken (2013)

4. Camilleri, G., Zaraté, P.: EasyMeeting: a group decision support system (Release 1). Rapport de recherche IRIT/RR-2014-10_FR (2014)

5. Moulin, H.: Axioms of Cooperative Decision Making (No. 15). Cambridge University Press, New York (1991)

6. Bostrom, R.P., Anson, R., Clawson, V.K.: Group facilitation and group support systems. Group Support Syst. New Perspect. 8, 146-168 (1993)

7. Ackermann, F.: Participants' perceptions on the role of facilitators using group decision support systems. Group Decis. Negot. 5(1), 93-112 (1996)

8. Yager, R.: On ordered weighted averaging aggregation operators in multicriteria decision making. IEEE Trans. Syst. Man Cybern. 18, 183-190 (1988)

9. Choquet, G.: Theory of capacities. Ann. Inst. Fourier 5, 131-295 (1953)

10. Schmidt, K., Bannon, L.: Taking CSCW seriously: supporting articulation work. Comput. Support. Coop. Work (CSCW) 1(1), 7-40 (1992)

11. Sibertin-Blanc, C., Zaraté, P.: Cooperative decision making: a methodology based on collective preferences aggregation. In: Zaraté, P., Kersten, G.E., Hernández, J.E. (eds.) GDN 2014. LNBIP, vol. 180, pp. 1-10. Springer, Heidelberg (2014)

12. Schwarz, R.: The skilled facilitator. Jossey-Bass Publishers (1994)

13. Ackermann, F., Eden, C.: Issues in computer and non-computer supported GDSSs. Decis. Support Syst. 12, 381-390 (1994)

14. French, S.: Web-enabled strategic GDSS, e-democracy and Arrow's theorem: a Bayesian perspective. Decis. Support Syst. 43(4), 1476-1484 (2007)

15. Limayem, L., DeSanctis, G.: Providing decisional guidance for multicriteria decision making in groups. Inf. Syst. Res. 11(4), 386-401 (2000)

16. Nunamaker, J., Briggs, R.O., Mittleman, D., Vogel, D., Balthazard, B.: Lessons from a dozen years of group support systems research: a discussion of lab and field findings. J. Manage. Inf. Syst. 13(3), 163-207 (1997) 